the complex links among sexuality, temporality, and history making" (23).

Valerie Traub

University of Michigan, Ann Arbor

\section{Sweden's OED}

\section{To THE EDITOR:}

I was delighted-nay, transfixed with patriotic elation - when I saw Ursula Lindqvist's essay “Majors and Minors in Europe's African Enterprise: Oyono's Une vie de boy in Danish and Swedish Translations"in the January 2013 issue of PMLA (128.1 [2013]: 149-55). However, my sense of jingoism diminished considerably, in a masochistically pleasurable, Coetzeean fashion, as I plumbed the depths of Lindqvist's eerily exhilarating exposé of Sweden's implication in the European colonial enterprise.
Perhaps my faultfinding is merely overcompensation, but, all the same: in the essay, the Swedish word kommisarie is misspelled; the correct spelling is kommissarie, as evidenced in the Swedish Academy's dictionary, known as the $S A O B$ ("Kommissarie"; Svenska Akademiens ordbook; Svenska Akademien, n.d.; Web; 21 May 2013). Once completed, the $S A O B$ will rival the $O E D$ (forgive my jingoism, obviously impervious to Lindqvist's crystalline logic).

I was, incidentally, fortunate enough to make a study visit to the Nordic Africa Institute (NAI) while earning my master's degree in library and information science. The NAI will never be quite the same for me since reading Lindqvist's essay.

Mattias Nyström Uppsala 